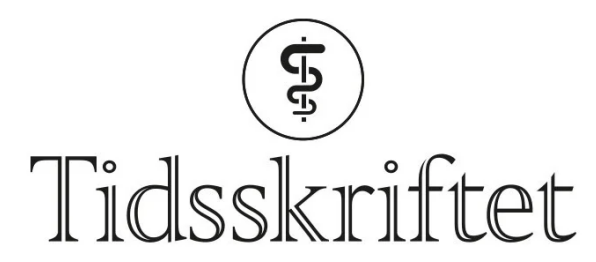

DEN NORSKE LEGEFORENING

\title{
Manipulasjonsbehandling mot akutte nakkesmerter?
}

DEBATT

\section{ALEKSANDER CHAIBI}

aleksander.chaibi@medisin.uio.no

Aleksander Chaibi er ph.d., kiropraktor og fysioterapeut ved Atlasklinikken og seniorforsker ved Avdeling for tverrfaglig helsevitenskap, Universitetet i Oslo.

Forfatteren har fylt ut ICMJE-skjemaet og oppgir ingen interessekonflikter.

\section{KNUT STAVEM}

Knut Stavem er professor i lungesykdommer ved Universitetet i Oslo og overlege på Lungemedisinsk avdeling, Akershus universitetssykehus.

Forfatteren har fylt ut ICMJE-skjemaet og oppgir ingen interessekonflikter.

\section{MICHAEL BJØRN RUSSELL}

Michael Bjørn Russell er professor i nevrologi ved Universitetet i Oslo og overlege på Nevrologisk avdeling, Akershus universitetssykehus.

Forfatteren har fylt ut ICMJE-skjemaet og oppgir ingen interessekonflikter.

\section{Manipulasjonsbehandling alene eller i kombinasjon med en annen behandling er effektivt ved akutte nakkesmerter. Bivirkningene er få, milde og forbigående.}

Nesten halvparten av verdens befolkning har nakkesmerter i løpet av et år, og rundt 40 \% rapporterer om nakkeplager de siste 30 dagene $(\mathbf{1}, \underline{2})$. Den globale punktprevalensen av aktivitetsbegrensende nakkesmerter av én dags varighet er beregnet til rundt $5 \%$ av befolkningen (3).

I to rapporter fra 2019 stipulerte man de totale kostnadene for muskel- og skjelettlidelser i Norge til henholdsvis 200 milliarder og minst 255 milliarder kroner per år i form av helsetap, tapt verdiskapning og behandlingskostnader alene. Rundt $85 \%$ av disse kostnadene er knyttet til nakke- og ryggplager $(4,5)$. Selv om disse beregningene og deres forutsetninger kan diskuteres, er det opplagt at individet og samfunnets kostnader for lidelser fra muskel- og skjelettsystemet er svært høye.

\section{Dagens behandlingspraksis}


I Norge oppsøker mange pasienter med nakkesmerter fastlege, fysioterapeut eller kiropraktor (5). Omkring en tredjedel av konsultasjonene hos fastleger er relatert til muskel- og skjelettplager ( $\underline{6}$ ). Ofte får pasientene forskrevet ikke-steroide antiinflammatoriske midler (NSAID), selv om det mangler vitenskapelig evidens for effekten ved nakkesmerter (7-9.). I en randomisert, placebokontrollert multisenterstudie undersøkte man effekten av NSAID-preparater for akutte nakkesmerter og fant at $400 \mathrm{mg}$ ibuprofen pluss $100 \mathrm{mg}$ koffein eller $400 \mathrm{mg}$ ibuprofen alene ikke var signifikant overlegen placebo (9).

Manuelle behandlere benytter ofte en kombinasjon av flere behandlingsmodaliteter i sin tilnærming, herunder leddmobilisering og/eller leddmanipulasjon, bløtvevsteknikker, treningsøvelser, rehabilitering, informasjon, rådgivning samt tiltak og råd om forebygging. Omkring $8 \%$ av pasienter med nakkeplager blir henvist fra lege til manuell behandling (10). Frykt for komplikasjoner forbundet med nakkemanipulasjon og begrenset vitenskapelig evidens for effekt virker å være førende og kan være en barriere for henvisning til slik behandling (10 $)$.

\section{Hva sier kunnskapsgrunnlaget?}

I en nylig publisert oversiktsartikkel i Journal of Clinical Medicine har vi vurdert evidensen av manipulasjonsbehandling for akutte nakkesmerter (111). Akutt ble her definert som nyoppståtte nakkesmerter som hadde vedvart i underkant av seks uker. Vi gjennomgikk en stor mengde fagfellevurderte artikler og inkluderte seks kliniske, randomiserte, kontrollerte studier. Det var stor heterogenitet mellom studiene, men de ga indikasjon på en viss behandlingseffekt av manipulasjonsbehandling mot smerte (11).

\section{"Selv om det synes å vare en effekt av manipulasjonsbehandling, er vi} samtidig bekymret for den lave kvaliteten på de inkluderte studiene»

Smerteintensitet i de randomiserte studiene ble målt med visuell analog skala (VAS) eller ordinal graderingsskala (NRS) på en skala fra o til 10, der o er ingen smerter og 10 maksimal smerte. Den samlede effektstørrelsen for reduksjon i smerteintensitet i de seks inkluderte studiene var-1,37 (95\% KI-2,41 til-0,34) i favør av manipulasjonsbehandling sammenlignet med kontrollpersoner (므). Effektstørrelse var her definert til $>0,2$ som liten,

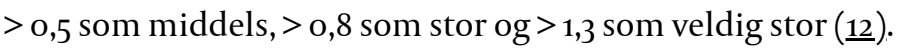

Én enkelt studie viste også bedre effekt på smerteintensitet av manipulasjonsbehandling enn behandling med NSAID-preparater (зo mg ketorolak intramuskulært) én dag etter behandling. Studiene viste få, milde eller forbigående bivirkninger av manipulasjonsbehandling.

Selv om det synes å være en effekt av manipulasjonsbehandling, er vi samtidig bekymret for den lave kvaliteten på de inkluderte studiene. Alle studiene hadde et pragmatisk design med manglende blinding og placebogruppe, og antallet inkluderte pasienter var lavt. Disse faktorene gir flere ubesvarte spørsmål omkring placeboeffekt. En annen utfordring er variasjonen i studiedesign og resultatmål, som medførte høy heterogenitet i resultatene. Dette begrenser naturligvis generaliserbarheten av funnene, og resultatene skal derfor tolkes med forsiktighet.

For å tette kunnskapshullene kreves mer robuste randomiserte, kliniske studier som tar hensyn til metodologiske svakheter for å oppnå så valide resultater som mulig. 


\section{LITTERATUR}

1. Carroll LJ, Hogg-Johnson S, van der Velde G et al. Course and prognostic factors for neck pain in the general population: results of the Bone and Joint Decade 2000-2010 Task Force on Neck Pain and Its Associated Disorders. Spine 2008; 33 (Suppl): S75-82. [PubMed][CrossRef]

2. Hogg-Johnson S, van der Velde G, Carroll LJ et al. The burden and determinants of neck pain in the general population: results of the Bone and Joint Decade 2000-2010 Task Force on Neck Pain and Its Associated Disorders. Spine 2008; 33 (Suppl): S39-51. [PubMed][CrossRef]

3. Hoy D, March L, Woolf A et al. The global burden of neck pain: estimates from the global burden of disease 2010 study. Ann Rheum Dis 2014; 73: 1309-15. [PubMed][CrossRef]

4. Skogli E, Theie MG, Stokke OM et al. Muskel- og skjelettsykdom i Norge: Rammer flest - Koster mest. Vurdering av tiltak for å redusere samfunnskostnadene. Menon-publikasjon nr. 31/2019. Oslo: Menon economics, 2019. https://www.menon.no/wp-content/uploads/2019-31-Rammer-flest-kostermest.pdf Lest 7.12.2021

5. Bærekraft i praksis. Samfunnskostnader og -utfordringer ved rygg- og nakkeplager i Norge, den viktigste årsaken til tapt helse og yrkesfravær. Oslo: Oslo Economics, 2019.

https://osloeconomics.no/wp-content/uploads/OE-rapport-2019-21-B\%C3\%A6rekraft-i-praksis.-Rygg-ognakkeplager-i-Norge.pdf Lest 7.12.2021

6. Kinge JM, Knudsen AK, Skirbekk V et al. Musculoskeletal disorders in Norway: prevalence of chronicity and use of primary and specialist health care services. BMC Musculoskelet Disord 2015; 16: 75. [PubMed][CrossRef]

7. Vos C, Verhagen A, Passchier J et al. Management of acute neck pain in general practice: a prospective study. Br J Gen Pract 2007; 57: 23-8. [PubMed]

8. Machado GC, Maher CG, Ferreira PH et al. Non-steroidal anti-inflammatory drugs for spinal pain: a systematic review and meta-analysis. Ann Rheum Dis 2017; 76: 1269-78. [PubMed][CrossRef]

9. Predel HG, Ebel-Bitoun C, Lange R et al. A randomized, placebo- and active-controlled, multicountry, multi-center parallel group trial to evaluate the efficacy and safety of a fixed-dose combination of $400 \mathrm{mg}$ ibuprofen and $100 \mathrm{mg}$ caffeine compared with ibuprofen $400 \mathrm{mg}$ and placebo in patients with acute lower back or neck pain. J Pain Res 2019; 12: 2771-83. [PubMed] [CrossRef]

10. Dikkers MF, Westerman MJ, Rubinstein SM et al. Why Neck Pain Patients Are Not Referred to Manual Therapy: A Qualitative Study among Dutch Primary Care Stakeholders. PLoS One 2016; 11: e0157465. [PubMed][CrossRef]

11. Chaibi A, Stavem K, Russell MB. Spinal manipulative therapy for acute neck pain: A systematic review and meta-analysis of randomised controlled trials. Journal Clinical Medicine 2021; 10: 21. [PubMed][CrossRef]

12. Cohen J. Statistical Power Analysis for the Behavioral Sciences. Cambridge, MA: Academic Press, 2013.

Publisert: 22. desember 2021. Tidsskr Nor Legeforen. DOI: 10.4045/tidsskr.21.0798

Mottatt 12.11.2021, første revisjon innsendt 25.11.2021, godkjent 1.12.2021.

(C) Tidsskrift for Den norske legeforening 2023. Lastet ned fra tidsskriftet.no 26. april 2023. 